\title{
DETERMINANT FACTORS OF TOURIST ATTRACTIVENESS OF GREEK PREFECTURES
}

\author{
S. POLYZOS ${ }^{1} \&$ G. ARABATZIS ${ }^{2}$ \\ ${ }^{1}$ Department of Planning and Regional Development, Engineering School, University of Thessaly, Greece. \\ ${ }^{2}$ Department of Forestry and Management of the Environment and Natural Resources, \\ Democritus University of Thrace, Greece.
}

\begin{abstract}
Tourism constitutes one of the most dynamic and rapidly developing sectors of the Greek economy, making a decisive contribution to the growth of many Greek regions. The increase in tourist flows to all regions of the country is a vital pursuit of its regional policies, and a means for achieving regional economic development. The intense differentiation in tourist arrivals at each individual prefecture of the country constitutes an issue that is related to the more general characteristics and factors that shape the degree of tourist attractiveness of each area. The present article examines the tourism characteristics of Greek prefectures and the factors that affect related tourist flows and define the structure of the country's internal tourism. Furthermore, a proposal is made as to the typology of the prefectures according to their tourist resources. The determination and the analysis of factors are performed by using the multiple regression statistical model, which calculates the impact of each individual determinant on the tourist attractiveness of the prefectures. Moreover, by using hierarchical cluster analysis, two uniform territorial units of tourist attractiveness are formed, thus giving the opportunity to decision-makers to exercise a more effective tourism and regional policy. The basic conclusion that results from the article is that the presence of sandy beaches and the sea vitally contributes to the configuration of each prefecture's overall tourist attractiveness.
\end{abstract}

Keywords: regional development, tourist flows, tourist resources.

\section{INTRODUCTION}

During the post-war period and especially after 1970, tourism has constituted one of the most dynamic and rapidly-developing sectors of the world economy, and has greatly influenced the shaping of the social and economic structure of tourist destinations, countries and regions. One of its main characteristics is the link between tourism operations and the internationalization affecting a large number of economic sectors, which has played a conducive role toward economic and regional development [1]. Relevant statistical data point toward a diachronic growth in international tourism, which is described as being not only rapid but also constant. Proof of this development is the fact that the total number of international tourist arrivals grew from 71 million in 1960 to 625.2 million in 1998, and is expected to reach 1018 million by 2010 [2]. In Greece, the total number of arrivals in 2003 amounted to $14,918,177$ people, as opposed to $11,230,854$ in 1994, thus representing an increase of $32.8 \%$ in a decade [3].

Greece is a country with rich economic, religious and intellectual activity for more than three and a half millennia, geographically spread on an archipelago of more than 2500 islands; located at the southeastern corner of Europe [4, 5]. It belongs geographically in the European Mediterranean Area, which is characterized by natural beauty, mild climate, cultural heritage and culture. This area is considered as the cradle of seasonal tourism and one of the most important international tourist destinations [6]. Moreover, Greece is one of the most remote, peripheral, insular and poor economic regions of the EU. Its tourism requires urgent strategic management action in order to compete with alternative destinations and maximize the prosperity of the host population. Similar strategic exercises are undertaken by competing destinations around the globe, as they prepare to face the new business realities [7].

(C) 2008 WIT Press, www.witpress.com

ISSN: 1743-7601 (paper format), ISSN: 1743-761X (online), http://journals.witpress.com DOI: $10.2495 / \mathrm{SDP}-\mathrm{V} 3-\mathrm{N} 4-343-366$ 
Tourism, both in Greece and other countries, is not a distinct, conventional economic sector, but rather a cluster of closely interdependent economic sectors that participate in the production of the tourism product. Many variable and unanticipated factors exist that can influence its development and create conditions of economic growth in tourist regions. As a new, quite particular and very rapidly evolving economic sector, it is directly connected to the social and cultural changes that take place in modern societies. This fact serves to explain the difficulties that exist in the conceptual delimitation and classification of the basic elements that put together the meaning of "tourism" [2, 8]. According to the generally accepted definition, also adopted in this paper, a "tourist" is considered any person who moves from his place of residence to another for a period of $24 \mathrm{~h}$, for reasons of recreation.

A concise review of the bibliography leads us to the conclusion that it contains a far greater number of references pertaining to international tourism, as opposed to internal tourism within a country. However, this fact comes into contrast with the number of arrivals or nights spent in a country by foreigners in relation to non-foreigners. For example, in Greece, the total number of nights Greek people spend in hotels is roughly 2.2 times higher than the number of nights spent by foreigners [9-11]. Although the number of nights spent by Greeks does not only involve tourist visits but also professional or other stays, which are not consequently related to tourism, nevertheless, internal tourism still remains an important issue. More generally, in all tourist destinations and particularly those that belong to the developed world, tourist regions can be identified in which the percentage of internal tourism exceeds that of external tourism.

Internal tourism has not yet been studied by researchers or competent organizations to the same extent as external or international tourism. The most rational explanation for the increased interest shown toward external tourism can be found in the connection between international tourism and economic growth, and the systematic promotion of the view that international tourism is the only kind of tourism that can contribute to a country's or region's economic growth, since it constitutes a source of foreign currency for the host country $[12,13]$. On the other hand, internal tourism is more closely connected to regional development, since it mainly operates by redistributing the economic wealth of a country, thus preventing the export of foreign currency. The limited research interest is also reinforced by the inexistence of sufficient statistical data and the general difficulty of statistically recording travel within a country's borders, when it is hard to distinguish between trips for tourism purposes and others (such as business trips) [14].

In many developed countries (USA, countries of Western Europe), several studies have been carried out to analyze the particular socioeconomic characteristics of tourist travels and the repercussions of internal tourism on regional development [15]. Moreover, studies and research have been carried out on certain categories-groups of tourists, such as those who camp out in the countryside, those who use campsites, tourists who have their own summer houses, etc. The study of these groups (incentives, travel characteristics, choices of regions, etc.) provides us with an interesting view of the parameters that determine the demand for internal tourism [16, 17]. In Greece, the spatial structure of international tourism and tourist flows from abroad to Greece has been examined in other articles $[2,18]$. However, internal tourism has not yet been extensively studied, and reservations have been expressed with regard to the possibility of constructing a model that examines traveling to sites of particular natural beauty for the purpose of recreation, since no documented theory exists concerning their manner or justification.

It has been proved that the contribution of internal tourism is indeed substantial and systematic in the case of special and alternative forms of tourism (urban tourism, social tourism, ecotourism, agrotourism, etc.) $[16,17,19]$. However, the role of this internal tourism category and its particular importance for local tourism growth have not yet been fully analyzed (reasons, motives) or evaluated (economic action), both nationally and globally. 
The fragmented scientific investigation of internal tourism leads to essential weaknesses in recording its contribution to various fields of development in a country or region. Although its systematic presence and its support of socioeconomic development are indubitable, we do not possess any valid or substantial evaluation of these parameters. Moreover, in several countries including Greece, it is extremely difficult to calculate the dimensions of internal tourism, since it is not always statistically documented, given the fact that one can either choose to stay in supplementary accommodation, or in unregistered lodgings, or with friends or relatives. Therefore, a systematic assessment of the contribution of internal tourism to economic development is lacking, resulting in an underestimation of its role in the national economy and in the functioning of the productive structure of tourist regions, and also as regards its contribution to local employment and regional development [20].

In general, internal tourism in Greece, which is calculated as the number of overnight stays spent in all types of accommodation, is expected to approximately reach 70 million nights by 2006 (compared to 45 million in 1996). Since there are insufficient statistical data, this can only be considered an estimate, and the forecasted increase is based on pending developments (regarding finance, support schemes for weaker social groups, etc.) that can influence demand. However, the tendency of Greek tourists, in the majority, to choose supplementary tourist units is expected to continue, due to their relatively lower level of prosperity compared with foreign tourists [20].

According to research carried out in Greece during the last few years, it has been observed that: (a) the percentage of Greeks who travel is constantly on the rise, while the largest majority choose Greece as their holiday destination. (b) The highest percentage of trips in Greece is made for holiday purposes, and many of these involve visits to friends and relatives. (c) A very limited number of people use travel agencies to organize their travels in Greece. (d) A particularly large number either use summer houses or stay at houses that are privately-owned or belong to friends and relatives during their holidays in Greece [20].

\section{LOCATION OF TOURISM}

Systematic research into the basic factors that shape individual and business decisions concerning the process of choosing a location, which is based on various spatial planning theories, can decisively contribute toward a more effective formulation of regional policy. A fuller knowledge of the parameters that influence the choice of location for the installation of a company can help in efficiently planning a policy, whose direct aim will be to primarily affect entrepreneurs and/or workers and persuade them to opt for "socially desirable places of installation" [21].

The first attempt to scientifically formulate a spatial planning theory was made by vön Thünen (1826), who dealt with the distribution of land use for cultivation around an urban center and formulated the theory of "concentric circles", which has since dominated general spatial planning policies. Later on, the establishment of economic activities in space was enriched with the theories of the classical school (Weber, Moses, Alonso, Losh, Isard, etc.). During the last 30 years, it has been examined by newer theories that focus on spatial planning for industries [22-24].

Contrary to agricultural and industrial activities, the question of finding the most suitable "economic space" for the installation of tourism and economic activities has occupied the minds of researchers in modern times, and more specifically in recent years; therefore, no relevant in-depth investigation has been undertaken to date. Neither the theories on the location of economic activities, nor economic geography or regional economy, have paid great attention to a study of tourism as a spatial phenomenon [18]. This development is possibly linked to two reasons: (a) Tourism constitutes a relatively new economic activity, since its rapid growth and the radical increase in tourist demand appeared after the 1960s, following the significant improvements in transport and the corresponding 
infrastructure; (b) choices of location are clearly much more limited in this case as compared to industry, since there are only specific geographic regions that possess the necessary tourist resources (climatic conditions, coasts, forests, archaeological and cultural locations, etc.). The development of tourism in a region presupposes the existence of natural or other advantages, some of which cannot always be secured $[14,19]$. Therefore, the solution to the problem of "localization" is considered a top priority by the tourism economy, as it is connected to the viability of tourism enterprises.

According to Christaller [25], in contrast to other economic activities, tourism is the sector of the economy, which avoids "central positions" and agglomeration economies. On the contrary, it is attracted by beaches, solitary forests and high mountains - areas that are geographically distant and isolated. The residents of over-populated urban centers choose to spend their free holiday time in regional zones, while visits to large cities are exclusively made for professional or educational reasons and incentives.

Von Boventer [26] disputes the force of Christaller's views and considers that the most important factors for tourism development in a region are transportation costs and agglomeration economies. Low transportation costs improve the overall accessibility of tourist regions and the agglomeration economies with their relevant activities impact on the amount and variety of services and goods provided to tourists, thus increasing the overall attractiveness of regions and affecting tourist flows.

A general overview of the bibliography and empirical studies leads us to the conclusion that tourism follows a complex route, despite the fact that a tendency of tourists to move from richer to poorer countries is observed on an international level. Domestic tourist flows also follow a similar pattern, since they usually emanate from urban centers and are directed toward regional areas with elements of tourist attractiveness. According to Pearce [27], research in various countries has shown that internal tourist flows are neither uniform nor random. Results on all scales confirm that flows are a decreasing function of distance, and that the internal tourist market cannot be viewed as a homogenous entity, as the diverse spatial preferences of domestic tourists indicate.

As regards the interdependencies that arise between the "center-region" relation and the direction of tourist flows, both on an international and national-regional level, they can be explained in connection with the economic supremacy of the center and the eagerness of regional areas to adopt values and solutions that will correspond to and satisfy the needs of the metropolitan traveler. Relevant research confirms the intraregional character of international tourist travel, and has proved that the "center" contributes to the growth of the regional tourism sector only to a small extent [2]. In general, tourism research is primarily focused on the reception countries (regions) and less on the countries (regions) that the tourist flows originate from.

In the following sections, we will define and analyze the factors that characterize tourist regions in Greece, influence flows toward them and which, in general, determine the spatial structure of internal tourism. Moreover, multiple regression functions will be used to measure the effect of those factors in shaping the amount of internal tourist flows, and various territorial units will be defined based on tourist resources that will be linked to the implementation of regional policies.

\section{FACTORS THAT INFLUENCE DOMESTIC TOURIST FLOWS IN GREECE}

The methodologies that have primarily been developed for the quantitative analysis of tourist flows can be classified into two basic categories [14, 18, 28, 29]: (a) The linear equation models of multiple regression. (b) The spatial interaction models that are mainly presented in the form of gravity models. The equations used are as follows: $T_{s r}=f\left(X_{1 r}, X_{2 r}, \ldots, X_{n r}\right)$, where $T_{s r}$ is the number of visitors of region $r$ and $X_{1 r}, X_{2 r}, \ldots, X_{n r}$ are the factors that create or attract tourist flows to $r$. 
More analytically, the models of the first category use the general form:

$$
T_{r}=a_{0}+\sum_{i=1}^{n} a_{i} X_{i r},
$$

where $T_{r}$ is the total number of visitors to region $r$ and $X_{i r}$ is the location factor that is related to more general characteristics of region $r$, which influences total tourist flows toward it.

The models of the second category use the general form:

$$
\mathrm{T}_{s r}=k P_{s}^{a} A_{r}^{b} \exp \left(c d_{s r}\right),
$$

where $\mathrm{T}_{s r}$ is the tourist flow from region $s$ (origin) to region $r$ (destination), $P_{s}$ is the regional factor (or factors) which produce tourist flows (e.g., prosperity level, etc.), $A_{r}$ is the indicator of total "attractiveness" of region $r, d_{s r}$ is the distance between $s$ and $r, K$ is the geographic constant, and $a$, $b$ and $c$ are parameters that show the elasticity of tourist flows in relation to the other variables.

A variation of the above model is the alternative opportunities model [28]. The general admission that arises from the use of linear equations concerns the linear function of tourist demand and the factors that define it. The basic differentiation of the two models lies in the different emphasis they place on the "distance" factor, the importance that is attributed to the "space" dimension and the nature of their interaction, which is reported in the pair relations of the geographic units of observation. Both the linear models, as well as the gravity models, usually use as basic factors that determine tourist flows: (a) the demographic and economic characteristics of the region which produces the flows. (b) The total "attractiveness" of the region, which "attracts" the flows. (c) The distance or the transportation costs connecting the regions of "production" and "attraction" of tourist flows. However, the application of the spatial interaction models requires statistical data that not only refer to the destination but also to the origin of the flows.

If we compare the available official statistical information concerning foreign tourist flows to Greece and internal tourist flows in Greece, we find that the former is much more comprehensive. Both the "destination" and the "origin" of foreign tourist flows can be determined by checking entry and exit data at ports, border stations and airports, as well as from the tourists' nationality which is recorded at their chosen accommodation. On the contrary, there is no corresponding record or statistical data concerning the region of origin of internal tourists in Greece; the only available statistical data are related to the "destination" of the Greek tourists.

Given the lack of information concerning the "origin" of internal tourists, the impact of each factor $F_{i}$ on formulating the total number of Greek visitors $T$ (from each of the remaining 50 prefectures of Greece) that travel to every individual prefecture $r$ will be examined by using the following equations:

$$
\begin{aligned}
& \sum_{s=1}^{50} T_{s r}=a_{0}+\sum_{i=1}^{n} a_{i} F_{i r} \\
& \sum_{s=1}^{50} T_{s r}=b_{0}+\prod_{i=1}^{n} F_{i r}^{b i} .
\end{aligned}
$$

Equation (3) is the same as eqn. (1), while eqn. (4) also takes into account any likely interdependence between the factors that shape tourist flows in each prefecture. The use of eqns. (3) and (4) first requires a description and a quantitative determination of the factors that determine the attractiveness and tourist interest of each region. In the present research, this analysis will be carried out on a prefectural level, and statistical data will be used concerning identical time periods. A cross-sectional 
analysis will therefore be performed, since the statistical data show that diachronically there are no significant relative changes in tourist flows, but rather a relative inactivity related to variations in the size, direction and spatial concentration of tourism. Consequently, the use of time series is not required.

Tourist flows and the quantitative estimate of tourism demand are usually measured in three ways [2], through: (a) The total expenses for tourism, (b) The tourist arrivals at tourist accommodation sites (numerical recording of arrivals at the countries' entry points for international tourism or at tourist lodgings for domestic tourism), (c) The total number of nights spent in all or certain tourist lodgings (recording of overnight stays by foreign and internal tourists). "Tourist lodging" refers to the area where the tourists are received, remain and spend the night.

For this investigation and the depiction of the dependent variable of eqns. (3) and (4), the total annual number of overnight stays in each prefecture $s$ is used, since the relevant statistical data exist and are particularly reliable [9-11]. The total number of overnight stays is a direct measure of the degree to which the productive capacity of the tourism sector is utilized, but is also an indicative measure of the total attractiveness of each region. It should be clarified that those visiting an area for tourism or other purposes are only taken into account when they spend at least one night in the region they are visiting.

Travel and overnight stays in a region are divided into three types mainly, depending on their purpose: commercial, business and for tourism or recreation. However, very often trips made for business or commercial reasons also include an element of leisure or recreation $[8,28]$. In the present research, through the use of eqns. (3) and (4), the following parameters will be used to depict the dependent variable (a) the number of overnight stays in all hotels in every prefecture, regardless of their purpose and (b) the nights spent at campsites, tourist lodgings, etc., which are sure to indicate trips made exclusively for recreational reasons.

Thereafter, there will be a description of the factors that we consider directly related to the formulation of the spatial structure of tourism activities. The relationship between the factors that shape the overall attractiveness of each prefecture and the total number of tourists that visit it, we consider to be obvious. Analytically, the factors are:

1. The population living around the recreation area, and its level of income or prosperity. Centers with a large population supply the recreation areas closest to them with a great number of visitors, therefore creating tourist flows of a relevant size toward them and vice versa. Consequently, we believe there is a positive relationship between the population surrounding such prefectures and the overall accessibility of the latter.

2. The distance of each prefecture from major centers, which are the starting points for tourist travel. Empirical analyses of International tourist flows have shown that "distance" is considered as the main factor that affects their pattern and spatial structure $[2,30]$. The predicted positive relationship comes into opposition with Christaller's opinion, i.e., that tourists seek to distance themselves from their surroundings and travel to "non-centrally located areas." The research that will ensue will serve to confirm or not the correctness of our initial hypotheses.

3. The environmental and more general characteristics of a region that encourage recreation and a pleasant stay. The natural and socio-cultural environment of each prefecture is what attributes the character of a tourist region to it, since it serves to satisfy the recreational and intellectual interests of its visitors. We therefore consider that there should obviously be a positive relationship between the tourist resources of a region and the total number of people that visit it.

4. The tourism infrastructure of the host prefecture. A region's general infrastructure constitutes a necessary precondition for it to receive visitors and offer them an enjoyable stay. 
5. The existence of other recreational areas in the same geographic region, which we believe may negatively influence the total amount of tourist flows to a prefecture, as it signifies that alternative choices or rival regions exist for each potential visitor. However, this may also have a positive repercussion on the tourism of a prefecture, by creating "economies of scale" and functioning in a complementary manner. In this case, the interdependence of the recreational prefectures is highlighted, along with their internal competition or complementarity in attracting tourist flows. The research that follows will shed light on the positive or negative effects of this factor.

We will now quantitatively analyze the above-mentioned factors, in order for values to be assigned to the relevant independent variables of the model. For the depiction of the first two factors in the model, i.e., the population, including its purchasing power, and its distance from the holiday region or the overall accessibility of the holiday regions, we use the notion of the economic potential. The economic potential of each prefecture is provided by the next equation: [31, 32]

$$
P_{s}=\sum_{r=1}^{50} M_{r}\left(d_{s r}^{-a}\right),
$$

where $P_{s}$ is the potential of prefecture $s, M_{r}$ is the measurement of the "mass" of economic activities, as they are expressed via the total purchasing power of each individual prefecture $r$ and $d_{s r}{ }^{-a}$ is the "resistance of friction" between the prefecture $s$ and the remaining prefecture $r$.

For the "resistance of friction" estimation the centroid time-distance between the prefectures will be used [33]. As regards exponent $\alpha$, other studies have used values ranging from 1.0 to 2.0 [29, 34]. In this study, two solutions will be given for eqns. (3) and (4), for values $\alpha=1.0$ and $a=1.5$, respectively. Since the visits to each prefecture, as was mentioned before, may not only be related to tourism, the solution with the number of overnight stays in hotels will also take into account the population of the host prefecture, on the assumption that these visits are proportional to the demographic size of the prefecture.

In order to portray the tourism characteristics or tourist resources of a prefecture, i.e., the more general characteristics of prefectures, which present an interest for tourists and "attract" tourist flows, we will first distinguish them into three basic categories. The first category involves the characteristics that are related to the existence of the sea, the second those related to the existence of mountains and the third includes the characteristics that are linked to the socio-cultural environment and traditions of each prefecture. More specifically, we will use the tourist resources indicator of each prefecture in our model, which is analyzed into a further four indicators, which are portrayed using separate variables. The tourist resources indicator is thus analyzed into: (a) the indicator of beaches, (b) the indicator of forest areas and sites of particular natural beauty (forest resources indicator), (c) the indicator of archaeological and cultural monuments, and (d) the indicator of traditional settlements.

The indicator of beaches refers to the total length of sandy beaches in each prefecture. There is the alternative solution of using the total length of coasts, but it is believed that the existence purely of coasts does not necessarily ensure their visibility and overall tourism exploitation potential. The indicator of forest areas and sites of particular natural beauty mainly refers to mountainous areas characterized by remarkable forests, national parks, striking landscapes, caves, thermal springs, etc. The indicator of archaeological and cultural monuments refers to antiquities and monuments of all times, while the indicator of traditional settlements refers to settlements with interesting traditional architectural elements and an important history. For the depiction of the tourist resources indicators, we use the values that were calculated by the National Land Use Plan of Greece, which are also included in other studies $[14,18,35]$. 
Another factor, which obviously affects tourism, is the total tourism infrastructure of each prefecture. For the resolution of the statistical model and the depiction of this variable, we use the total number of beds in hotels of all categories plus the number of beds in tourist lodgings in each prefecture [9-11].

Finally, with regard to the spatial interaction of the regions, we will use a "tourism potential" or "recreation potential" indicator for each prefecture. This indicator is proportional to the population or economic potential indicator and presents the total tourism potential of each region or otherwise the measure of proximity of holiday regions. It was estimated by using eqn. (5), where, in the place of "mass" $M_{r}$, the indicator of the prefectures' beaches was used, since statistical data have shown that beaches are a basic tourist resource, which seems to decisively influence tourism.

Thus, we use the following equations for our research:

$$
\begin{aligned}
\sum_{s=1}^{50} T_{s r}= & a_{0}+a_{1}(\mathrm{BEAC})_{r}+a_{2}(\mathrm{NAT})_{r}+a_{3}(\mathrm{ARC})_{r}+a_{4}(\mathrm{TRAD})_{r}+a_{5}(\mathrm{POT})_{r}+a_{6}(\mathrm{POP})_{r} \\
& +a_{7}(\mathrm{TPOT})_{r}+a_{8}(\mathrm{INF})_{r}+\varepsilon_{r}, \quad \varepsilon_{r} \sim\left(0, \sigma_{\varepsilon}^{2}\right)
\end{aligned}
$$

where $\sum_{s=1}^{50} T_{s r}$ is the overall tourist attractiveness of prefecture $r$, (BEAC) is the indicator of beaches, (NAT) is the indicator of forest areas and sites of natural beauty, (ARC) is the indicator of archaeological resources, (TRAD) is the indicator of traditional settlements, (TPOT) is the indicator of tourism potential, (POP) is the population of each prefecture, (POT) is the economic potential of each prefecture and (INF) is the tourism infrastructure.

In order to define uniform spatial units based on the prefectures' tourist resource indicators and configure a map of Greece's identity regarding tourism, for the purpose of exercising an effective regional and tourism policy, the cluster analysis statistical methodology was used. More precisely, we have used indicators of beaches, natural (forest) resources, cultural resources and traditional settlements in each prefecture.

Cluster analysis uses graphic techniques and algorithms in order to separate objects (variables or data) into clusters. A study of the data in order to identify a structural or natural grouping is an important research technique. Groupings can constitute a means of formulating interesting hypotheses that refer to the way in which data are related. Cluster analysis does not include hypotheses that refer to the number of clusters or their structure. Groupings are made based on similarities or distances. The tools required measure similarities or data for which similarities can be estimated. Cluster analysis can either be performed using the techniques of hierarchical cluster analysis or the technique of $K$-means cluster analysis. If hierarchical cluster analysis is used, successive agglomerations or subdivisions of the data are formed. One of the main characteristics of the hierarchical cluster analysis techniques is that the registration of an object (of observation) into a cluster is irreversible [36, 37].

In the context of this paper, we applied the hierarchical cluster analysis technique and more specifically the Ward method. As a criterion of distance for this method, we used the Eucledian distance. When using the Ward method, clusters are formed in such a way that the variability within them is minimized [36]. The analysis was based on the 51 prefectures of Greece and the variables used were the three above-mentioned indicators of tourist attractiveness.

\section{RESULTS}

We evaluate the multiple regression eqns. (6) and (7) with the OLS method and by using, as was mentioned before, data concerning the 51 prefectures of Greece. We evaluate the equations for the 
following alternative cases: (a) for nights spent in hotels, (b) for nights spent in supplementary tourist units, (c) for the value $a=1$, and (d) for the value $a=1.5$ in eqn. (5). The results of the estimations of the parameters in eqns. (6) and (7) and the significance test are presented in detail in Tables 1 and 2. Also, in Tables 3-6 we see the correlation coefficients between the model variables and their degree of significance for all the above-mentioned cases.

With regard to the results of the estimations, we can generally say that the overall explanatory power, as expressed by the coefficient of determination $\left(R^{2}\right.$ and $R^{2}$-adjusted), is considered to be satisfactory for nights spent in hotels, and not so satisfactory for nights spent in supplementary tourist units, given the cross-sectional type of the statistical data. The values of the calculated estimators confirm our initial expectations concerning the positive contribution of the determinants to the formulation of the level of tourist flows or the tourist attractiveness of prefectures, only in certain cases. The results of the estimation for each variable are analyzed below.

From Tables 3-6, we realize that the correlation coefficients between the independent variables have satisfactory values and therefore, no multicollinearity is observed in the model. High values in the correlation coefficients are presented by variable POP with variables ARC and TPOT. This is considered quite reasonable. Moreover, the tables of the estimation of the correlation give us some conclusions concerning the interdependence between the independent variables of the model.

An overall evaluation of the results of this study points to the fact that there seems to be a significant differentiation between them for the four cases that were examined. In general, the statistical significance is not satisfactory for all the cases, while estimators of parameters are present with opposite signs in the different solutions given to the equations.

A broad review of the results of the estimations leads us to the conclusion that the factors that "attract" visitors to prefectures, in line with the given solutions, are beaches, tourism infrastructure and the existence of large population centers. The estimations gave positive values to the parameters' estimators of variables BEAC, INF and POP, through which these factors were depicted, and the statistical significance was satisfactory.

Given the fact that we are examining the total number of overnight stays in each prefecture, many of which are not related to tourism, the results for the three variables are evaluated as reasonable. Tourism in Greece is a "summer phenomenon," which means that tourists are attracted by coastal areas and the sea and their primary destination are coastal prefectures and sandy beaches. The tourist demand that is thus created leads to the construction of tourism infrastructure that strengthens the existing demand. For this reason, we observe high values in the correlation between the variables BEAC and INV. Finally, urban centers attract visitors for tourism, business or commercial reasons, which is why the population size of a prefecture is positively linked to the creation of proportional flows.

In what concerns the contribution of the remaining natural, social and cultural resources of the prefectures that are portrayed with variables NAT, ARC and TRAD, traditional settlements seem to influence the tourist attractiveness of prefectures. In all solutions, the variable TRAD is shown to have a positive influence with a satisfactory statistical significance. On the contrary, the variables NAT and ARC appear statistically insignificant, while the relevant coefficients have positive values except for one solution in which they have negative values. This serves to underline that both natural beauty and the existence of archaeological sites influence tourism positively, but not to a great extent.

The results indicate that the variable POT appears statistically significant and its coefficient has positive values in all solutions. This leads to the conclusion that the economic potential positively influences the creation of tourist flows to the prefectures, a view that coincides with the opinions of vön Boventer regarding the importance of distance or transportation costs for tourism. Consequently, 


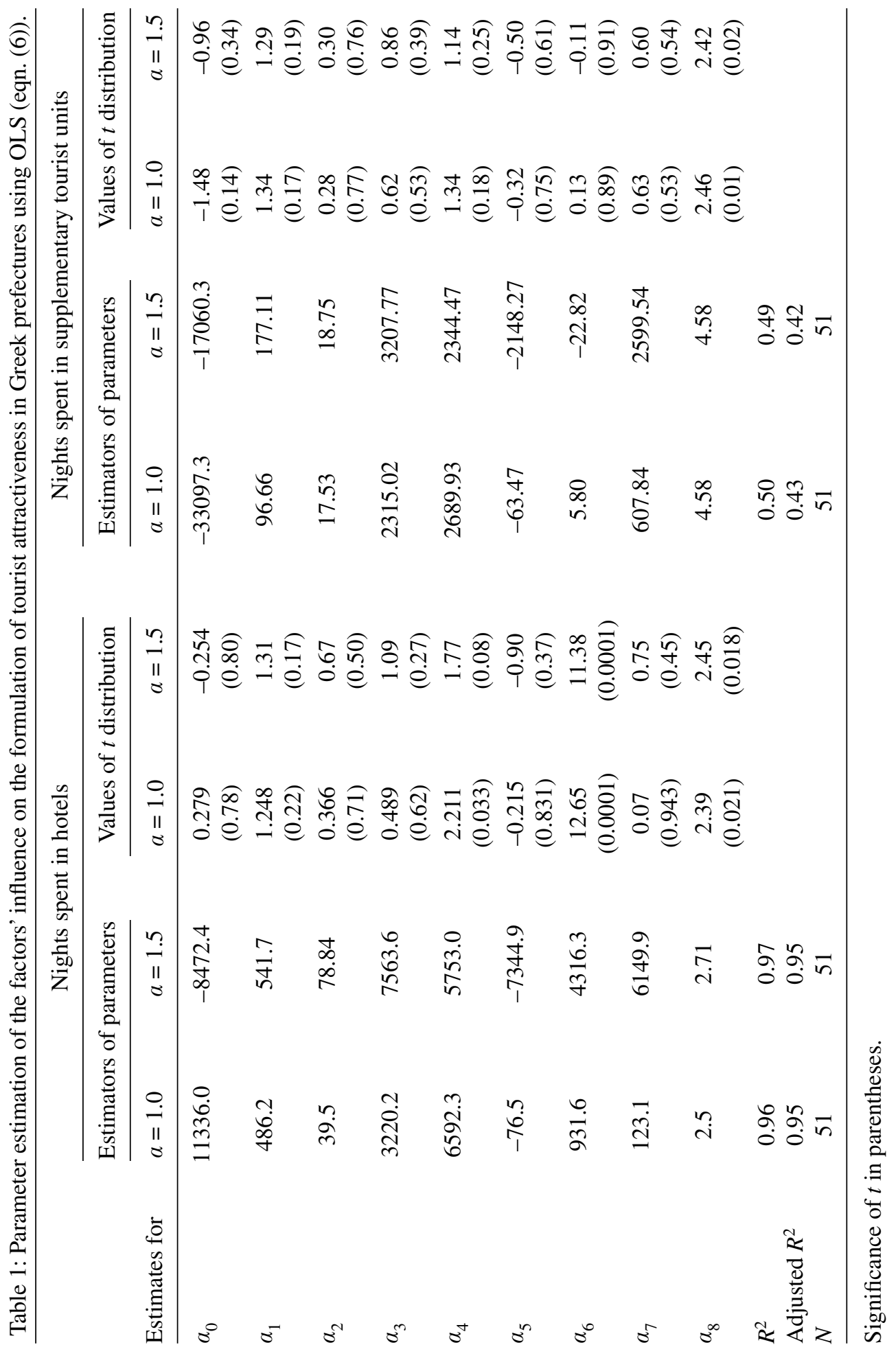




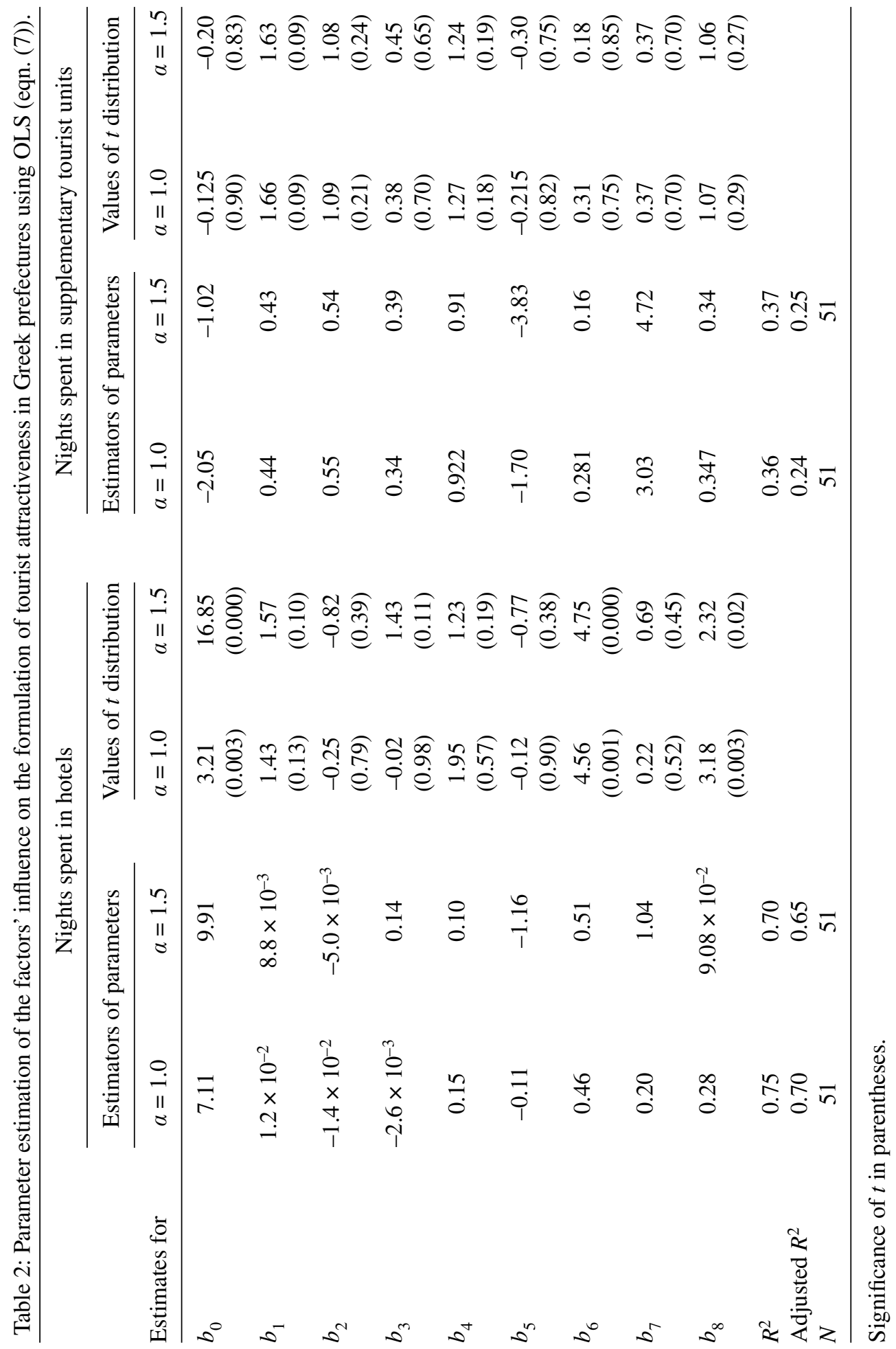


Table 3: Correlation coefficients between the variables of eqn. (6) for nights spent in hotels.

\begin{tabular}{lcccccccc}
\hline & $(\mathrm{BEAC})$ & $(\mathrm{NAT})$ & $(\mathrm{ARC})$ & $(\mathrm{TRAD})$ & $(\mathrm{POT})$ & $(\mathrm{POP})$ & $(\mathrm{TPOT})$ & $(\mathrm{INF})$ \\
\hline (BEAC) & $\mathbf{1 . 0 0 0}$ & -0.140 & -0.097 & 0.106 & $-0.330^{*}$ & -0.218 & $-0.298^{*}$ & 0.131 \\
& & $(0.327)$ & $(0.498)$ & $(0.460)$ & $(0.018)$ & $(0.125)$ & $(0.013)$ & $(0.358)$ \\
(NAT) & -0.140 & $\mathbf{1 . 0 0 0}$ & -0.203 & -0.176 & 0.041 & -0.124 & 0.037 & -0.162 \\
& $(0.327)$ & & $(0.153)$ & $(0.216)$ & $(0.777)$ & $(0.387)$ & $(0.795)$ & $(0.255)$ \\
(ARC) & -0.097 & -0.203 & $\mathbf{1 . 0 0 0}$ & $0.437^{*}$ & 0.159 & $0.574^{* *}$ & 0.256 & $0.592^{* *}$ \\
& $(0.498)$ & $(0.153)$ & & $(0.001)$ & $(0.264)$ & $(0.000)$ & $(0.070)$ & $(0.000)$ \\
(TRAD) & 0.106 & -0.176 & $0.437^{*}$ & $\mathbf{1 . 0 0 0}$ & -0.170 & -0.015 & -0.159 & $0.442^{*}$ \\
& $(0.460)$ & $(0.226)$ & $(0.001)$ & & $(0.233)$ & $(0.917)$ & $(0.266)$ & $(0.001)$ \\
(POT) & $-0.330^{*}$ & 0.041 & 0.159 & -0.170 & $\mathbf{1 . 0 0 0}$ & 0.021 & $0.698^{* *}$ & -0.303 \\
& $(0.018)$ & $(0.777)$ & $(0.264)$ & $(0.233)$ & & $(0.884)$ & $(0.000)$ & $(0.031)$ \\
(POP) & -0.218 & -0.124 & $0.574^{* *}$ & -0.015 & 0.021 & $\mathbf{1 . 0 0 0}$ & 0.150 & $0.552^{*}$ \\
& $(0.125)$ & $(0.387)$ & $(0.000)$ & $(0.917)$ & $(0.884)$ & & $(0.294)$ & $(0.000)$ \\
(TPOT) & $-0.298^{* *}$ & 0.037 & 0.256 & -0.159 & $0.698^{* *}$ & 0.150 & $\mathbf{1 . 0 0 0}$ & -0.214 \\
& $(0.013)$ & $(0.795)$ & $(0.070)$ & $(0.266)$ & $(0.000)$ & $(0.294)$ & & $(0.131)$ \\
(INF) & 0.131 & -0.162 & $0.592^{* *}$ & $0.442^{* *}$ & -0.303 & $0.552^{*}$ & -0.214 & $\mathbf{1 . 0 0 0}$ \\
& $(0.358)$ & $(0.255)$ & $(0.000)$ & $(0.001)$ & $(0.031)$ & $(0.000)$ & $(0.131)$ & \\
\hline
\end{tabular}

The numbers in italics correspond to case $\alpha=1.5$, and the others to case $a=1.0$.

"Correlation is significant at the 0.05 level (two-tailed).

${ }^{* *}$ Correlation is significant at the 0.01 level (two-tailed).

the effect of distance is positive and statistically significant in formulating the overall tourist attractiveness of each region.

The variable TPOT appears with positive coefficients in all solutions, but is statistically insignificant. Therefore, we cannot say with certainty that complementarity or competitiveness exists between the tourist resources of prefectures. It should be noted that only the coasts of prefectures, and no other tourist resources, were used to create the "tourism potential" indicator. Moreover, since the variable TPOT presents an extended linear correlation with the other variables, we do not consider the results of calculating the corresponding coefficient reliable, and, consequently, we cannot comment on its overall effect on tourist flows. As was mentioned above, it was included in the model in order to show the interaction between the tourist regions and thus make up for the model's weakness in evaluating their interaction, a result that is ensured with the use of models of spatial interdependence.

We can also observe from the results of the estimations the important differences that exist between the alternative solutions. The solutions that were given using two different values for exponent $\alpha$, and consequently a different relationship between the "imagined" and actual distance, showed that the effect of distance on tourist flows depends on the value of $\alpha$. We can therefore say that distance does play a certain role and influence tourist flows, but it does not constitute the most important factor. A small improvement to the transport infrastructure and the related changes to the overall distance and population potential of a region are not certain to have a remarkable effect on its level of tourism.

It is possible that other factors also exist, aside from the ones included in the models, like advertising, promotional activities, greater mobility and the entrepreneurship of the tourist bodies that affect the development of tourism in each prefecture. However, such factors cannot be easily 
Table 4: Correlation coefficients between the variables of eqn. (6) for nights spent in supplementary tourist units.

\begin{tabular}{lcccccccc}
\hline & $(\mathrm{BEAC})$ & $(\mathrm{NAT})$ & $(\mathrm{ARC})$ & $(\mathrm{TRAD})$ & $(\mathrm{POT})$ & $(\mathrm{POP})$ & $(\mathrm{TPOT})$ & $(\mathrm{INF})$ \\
\hline (BEAC) & $\mathbf{1 . 0 0}$ & -0.140 & -0.097 & 0.106 & $-0.292^{*}$ & -0.218 & $-0.298^{*}$ & $0.379^{*}$ \\
& & $(0.327)$ & $(0.498)$ & $(0.460)$ & $(0.018)$ & $(0.125)$ & $(0.034)$ & $(0.006)$ \\
$(\mathrm{NAT})$ & -0.140 & $\mathbf{1 . 0 0}$ & -0.203 & -0.176 & 0.041 & -0.124 & 0.037 & -0.174 \\
& $(0.327)$ & & $(0.153)$ & $(0.216)$ & $(0.777)$ & $(0.387)$ & $(0.795)$ & $(0.223)$ \\
$(\mathrm{ARC})$ & -0.097 & -0.203 & $\mathbf{1 . 0 0}$ & $0.437^{*}$ & 0.159 & $0.587^{* *}$ & 0.256 & 0.247 \\
& $(0.491)$ & $(0.153)$ & & $(0.001)$ & $(0.264)$ & $(0.000)$ & $(0.070)$ & $(0.080)$ \\
$(\mathrm{TRAD})$ & 0.106 & -0.176 & $0.437^{*}$ & $\mathbf{1 . 0 0}$ & -0.170 & -0.015 & -0.159 & $0.630^{* *}$ \\
& $(0.460)$ & $(0.216)$ & $(0.001)$ & & $(0.233)$ & $(0.917)$ & $(0.266)$ & $(0.000)$ \\
(POT) & $-0.292^{*}$ & 0.041 & 0.159 & -0.170 & $\mathbf{1 . 0 0}$ & 0.108 & $0.679^{* *}$ & $-0.283^{*}$ \\
& $(0.018)$ & $(0.777)$ & $(0.264)$ & $(0.233)$ & & $(0.452)$ & $(0.000)$ & $(0.044)$ \\
(POP) & -0.218 & -0.124 & $0.587^{* *}$ & -0.015 & 0.108 & $\mathbf{1 . 0 0}$ & 0.162 & 0.051 \\
& $(0.125)$ & $(0.387)$ & $(0.000)$ & $(0.917)$ & $(0.452)$ & & $(0.255)$ & $(0.720)$ \\
$(\mathrm{TPOT})$ & $-0.298^{*}$ & 0.037 & 0.256 & -0.159 & $0.679^{* *}$ & 0.162 & $\mathbf{1 . 0 0}$ & -0.235 \\
& $(0.034)$ & $(0.795)$ & $(0.070)$ & $(0.266)$ & $(0.000)$ & $(0.255)$ & & $(0.097)$ \\
$(\mathrm{INF})$ & $0.379^{* *}$ & -0.174 & 0.247 & $0.630^{* *}$ & $-0.283^{*}$ & 0.051 & -0.235 & $\mathbf{1 . 0 0}$ \\
& $(0.006)$ & $(0.223)$ & $(0.080)$ & $(0.000)$ & $(0.044)$ & $(0.720)$ & $(0.097)$ & \\
\hline
\end{tabular}

The numbers in italics correspond to case $a=1.5$, and the others to case $a=1.0$.

"Correlation is significant at the 0.05 level (two-tailed).

${ }^{* *}$ Correlation is significant at the 0.01 level (two-tailed).

quantified and included in a model. Moreover, they are variable factors, whose impact depends on their degree of differentiation; lastly, such factors are not necessarily present in each prefecture.

Finally, as seen from Fig. 1, five territorial units/clusters resulted from the cluster analysis. The basic characteristics of these clusters are presented in Table 7. The first territorial unit/cluster consists of one prefecture (Attiki). This cluster has the highest indicators for cultural monuments and monuments of international interest, compared with all the other clusters. This cluster is dominated by the model of cultural and sports tourism. Attiki maintains a high position on an international and national scale due to its cultural resources, thus constituting a pole of cultural tourism. More specifically, many great cultural and sports infrastructural projects have been created in Attiki in recent years. The modernization and renovation of existing museums, the restoration of remarkable historical buildings, the improvement and upgrading of the natural environment in combination with relevant cultural events, the creation of new types of museums for the preservation of our social, folkloric and ecological heritage, major sports events like the Olympic games, grand international exhibitions, festivals and other cultural events have all contributed considerably to the development of cultural and sports tourism.

In the second territorial unit/cluster, we find 17 prefectures. All the prefectures in this cluster constitute coastal and island regions. This cluster, in comparison with the others, does not predominate in relation to any indicator. Its prefectures are characterized by the model of mass holiday tourism. The social and productive structure of many of these regions depends to a great extent on the growth 
Table 5: Correlation coefficients between the variables of eqn. (7) for nights spent in hotels.

\begin{tabular}{lcccccccc}
\hline & $\ln (\mathrm{BEAC})$ & $\ln (\mathrm{NAT})$ & $\ln (\mathrm{ARC})$ & $\ln (\mathrm{TRAD})$ & $\ln (\mathrm{TPOT})$ & $\ln (\mathrm{POP})$ & $\ln (\mathrm{POT})$ & $\ln (\mathrm{INF})$ \\
\hline $\ln (\mathrm{BEAC})$ & $\mathbf{1 . 0 0}$ & $-0.322^{*}$ & 0.233 & $0.519^{* *}$ & -0.221 & 0.008 & -0.233 & $0.596^{* *}$ \\
& & $(0.021)$ & $(0.104)$ & $(0.000)$ & $(0.119)$ & $(0.957)$ & $(0.100)$ & $(0.000)$ \\
$\ln (\mathrm{NAT})$ & $-0.322^{*}$ & $\mathbf{1 . 0 0}$ & $-0.353^{*}$ & $-0.369^{* *}$ & 0.236 & $-0.305^{*}$ & 0.200 & $-0.485^{* *}$ \\
& $(0.021)$ & & $(0.012)$ & $(0.008)$ & $(0.096)$ & $(0.030)$ & $(0.160)$ & $(0.000)$ \\
$\ln (\mathrm{ARC})$ & 0.233 & $-0.353^{*}$ & $\mathbf{1 . 0 0}$ & $0.478^{* *}$ & 0.182 & $0.532^{* *}$ & 0.210 & $0.565^{* *}$ \\
& $(0.104)$ & $(0.012)$ & & $(0.000)$ & $(0.205)$ & $(0.000)$ & $(0.144)$ & $(0.000)$ \\
$\ln (\mathrm{TRAD})$ & $0.519^{* *}$ & $0.369^{* *}$ & $0.478^{* *}$ & $\mathbf{1 . 0 0}$ & $0 . .267$ & 0.078 & -0.253 & $0.554^{* *}$ \\
& $(0.000)$ & $(0.008)$ & $(0.000)$ & & $(0.058)$ & $(0.586)$ & $(0.074)$ & $(0.000)$ \\
$\ln (\mathrm{TPOT})$ & -0.221 & 0.236 & 0.182 & 0.267 & $\mathbf{1 . 0 0}$ & $0.313^{*}$ & $0.589^{* *}$ & $-0.297^{*}$ \\
& $(0.119)$ & $(0.096)$ & $(0.205)$ & $(0.058)$ & & $(0.025)$ & $(0.000)$ & $(0.034)$ \\
$\ln (\mathrm{POP})$ & 0.008 & $-0.305^{*}$ & $0.532^{* *}$ & 0.078 & $0.313^{*}$ & $\mathbf{1 . 0 0}$ & 0.262 & $0.373^{* *}$ \\
& $(0.957)$ & $(0.030)$ & $(0.000)$ & $(0.586)$ & $(0.025)$ & & $(0.063)$ & $(0.007)$ \\
$\ln (\mathrm{POT})$ & -0.233 & 0.200 & 0.210 & -0.253 & $0.589^{* *}$ & 0.262 & $\mathbf{1 . 0 0}$ & -0.252 \\
& $(0.100)$ & $(0.160)$ & $(0.144)$ & $(0.074)$ & $(0.000)$ & $(0.063)$ & & $(0.074)$ \\
$\ln (\mathrm{INF})$ & $0.596^{* *}$ & $-0.485^{* *}$ & $0.565^{* *}$ & $0.554^{* *}$ & $-0.297^{*}$ & $0.373^{* *}$ & -0.252 & $\mathbf{1 . 0 0}$ \\
& $(0.000)$ & $(0.000)$ & $(0.000)$ & $(0.000)$ & $(0.034)$ & $(0.007)$ & $(0.074)$ & \\
\hline
\end{tabular}

The numbers in italics correspond to case $\alpha=1.5$, and the others to case $a=1.0$.

*Correlation is significant at the 0.05 level (two-tailed).

**Correlation is significant at the 0.01 level (two-tailed).

of tourism. The progressive abandonment of other productive sectors of the economy for the benefit of tourism renders it a prominent force in the economic life of these regions. In such cases, this dependence is somewhat restricting, since a high percentage of the tourism demand originates from foreign tourists coming from a small number of countries, a large share of the demand is directly or indirectly linked to a limited number of tour-operators and many of these regions are characterized by a highly seasonal, short period of tourism.

The third territorial unit/cluster comprises 28 prefectures, located in various regions of the Greek mainland and islands. This cluster, like the previous one, does not predominate in relation to any indicator. In this territorial unit, the model of mass tourism and countryside tourism prevails, particularly special and alternative forms of tourism (agrotourism, ecotourism, mountainous tourism, etc.).

The basic characteristics of the mass tourism model are the extended, organized infrastructure and services it provides, and the seasonal demand which peaks in summertime. Furthermore, the impact of the model on the productive structure of the region is decisive, and results in almost all remaining sectors becoming gradually dependent on tourism, whose growth often negatively affects the local society, economy and the environment. A large part of the demand concerns organized "package tours" promoted by tour-operators. Also, in recent decades a significant increase in the demand for summerhouses has been observed in coastal areas, primarily in the vicinity of large urban centers [28].

The characteristics of the model for countryside tourism are the small-size tourist units that are adapted to the natural and architectural environment, the quality of the provided goods and services, the differentiation of activities in rural areas, the guarantee of a supplementary income for farmers, 
Table 6: Correlation coefficients between the variables of eqn. (7) for nights spent in supplementary tourist units.

\begin{tabular}{lcccccccc}
\hline & $\ln (\mathrm{BEAC})$ & $\ln (\mathrm{NAT})$ & $\ln (\mathrm{ARC})$ & $\ln (\mathrm{TRAD})$ & $\ln (\mathrm{TPOT})$ & $\ln (\mathrm{POP})$ & $\ln (\mathrm{POT})$ & $\ln (\mathrm{INF})$ \\
\hline $\ln (\mathrm{BEAC})$ & $\mathbf{1 . 0 0}$ & $-0.322^{*}$ & 0.233 & $0.519^{* *}$ & -0.221 & 0.008 & -0.233 & $0.637^{* *}$ \\
& & $(0.021)$ & $(0.104)$ & $(0.000)$ & $(0.119)$ & $(0.957)$ & $(0.100)$ & $(0.000)$ \\
$\ln (\mathrm{NAT})$ & $-0.322^{*}$ & $\mathbf{1 . 0 0}$ & $-0.353^{*}$ & $-0.369^{* *}$ & 0.236 & -0.270 & 0.200 & -0.252 \\
& $(0.021)$ & & $(0.012)$ & $(0.008)$ & $(0.096)$ & $(0.055)$ & $(0.160)$ & $(0.075)$ \\
$\ln (\mathrm{ARC})$ & 0.233 & $-0.353^{*}$ & $\mathbf{1 . 0 0}$ & $0.478^{* *}$ & 0.182 & $0.532^{* *}$ & 0.210 & $0.299^{* *}$ \\
& $(0.104)$ & $(0.012)$ & & $(0.000)$ & $(0.205)$ & $(0.000)$ & $(0.144)$ & $(0.035)$ \\
$\ln (\mathrm{TRAD})$ & $0.519^{* *}$ & $-0.369^{* *}$ & $0.478^{* *}$ & $\mathbf{1 . 0 0}$ & -0.266 & 0.028 & -0.253 & $0.516^{* *}$ \\
& $(0.000)$ & $(0.008)$ & $(0.000)$ & & $(0.059)$ & $(0.845)$ & $(0.074)$ & $(0.000)$ \\
$\ln (\mathrm{TPOT})$ & -0.221 & 0.236 & 0.182 & -0.267 & $\mathbf{1 . 0 0}$ & 0.313 & $0.630^{* *}$ & -0.262 \\
& $(0.119)$ & $(0.096)$ & $(0.205)$ & $(0.058)$ & & $(0.025)$ & $(0.000)$ & $(0.063)$ \\
$\ln (\mathrm{POP})$ & 0.008 & -0.270 & $0.532^{* *}$ & 0.028 & 0.313 & $\mathbf{1 . 0 0}$ & $0.335^{*}$ & 0.048 \\
& $(0.957)$ & $(0.055)$ & $(0.000)$ & $(0.845)$ & $(0.025)$ & & $(0.016)$ & $(0.738)$ \\
$\ln (\mathrm{POT})$ & -0.233 & 0.200 & 0.210 & -0.253 & $0.630^{* *}$ & $0.335^{*}$ & $\mathbf{1 . 0 0}$ & -0.255 \\
& $(0.100)$ & $(0.160)$ & $(0.144)$ & $(0.074)$ & $(0.000)$ & $(0.016)$ & & $(0.071)$ \\
$\ln (\mathrm{INF})$ & $0.637^{* *}$ & -0.252 & $0.299^{*}$ & $0.516^{* *}$ & -0.262 & 0.048 & -0.255 & $\mathbf{1 . 0 0}$ \\
& $(0.000)$ & $(0.075)$ & $(0.035)$ & $(0.00)$ & $(0.063)$ & $(0.738)$ & $(0.071)$ & \\
\hline
\end{tabular}

The numbers in italics correspond to case $\alpha=1.5$, and the others to case $\alpha=1.0$.

*Correlation is significant at the 0.05 level (two-tailed).

**Correlation is significant at the 0.01 level (two-tailed).

the promotion of the local economic potential and the major benefits that are gained for the local economy $[38,39]$. Simultaneously however, a particularly competitive relationship between agriculture and tourism is beginning to emerge in several of these regions, and new urban-type social and productive relations are being created within the context of tourism development.

The fourth territorial unit/cluster includes three prefectures (Fthiotida, Ioannina, Grevena) that are characterized by a high percentage of forest coverage and the existence of national parks (Iti, Vikos-Aoos, Pindos). This territorial unit has the highest indicators of forest areas and national parks in comparison with the other territorial units. In these prefectures, the model of mountain tourism and ecotourism prevails. The national parks and the protected areas in general, do not involve in their totality the absolute protection of nature and do not only aim at promoting the conservation of ecosystems and species. They also contain other substantial values and are called upon to serve other important functions in parallel, of a smaller or greater intensity, mainly those linked to receiving the public and satisfying people's needs, in relation to providing recreation in the countryside, and an appreciation of nature and the surrounding landscape. These regions operate as poles of attraction for an increasing number of visitors that participate in a form of ecotourism. What attracts visitors to these regions is the incomparable natural environment and the rare scenic beauty [40].

At the same time, protected regions have created an additional income and employment for the local societies, by exploiting the increasing demand for ecotourism. More specifically, the benefits from the growth of this tourist model are the inflow of foreign and local currency from foreign and Greek visitors, respectively, the diversification and strengthening of the local economy, particularly 


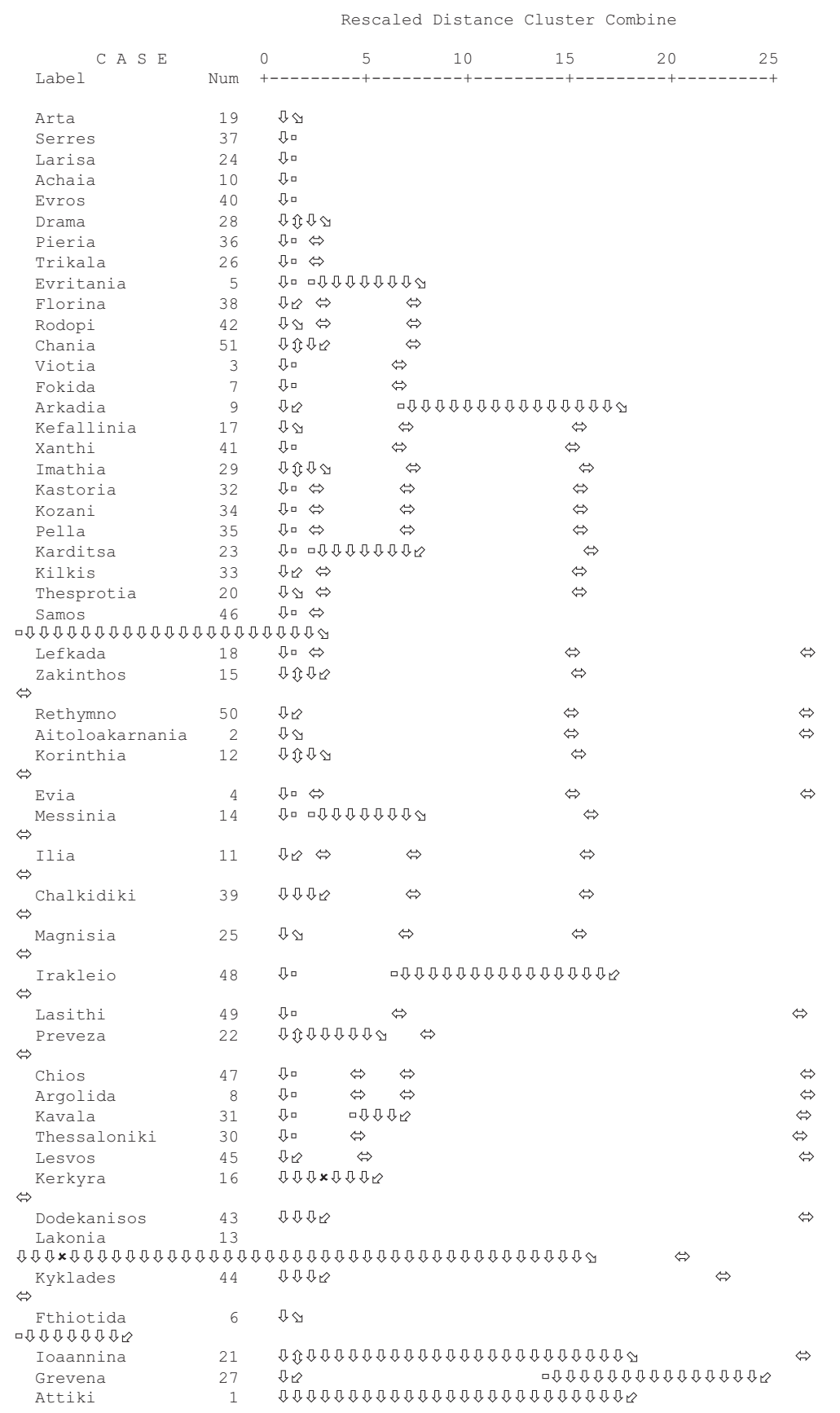

Figure 1: Results of cluster analysis on the basis of indicators of tourist indicators. 
S. Polyzos \& G. Arabatzis, Int. J. Sus. Dev. Plann. Vol. 3, No. 4 (2008)

359

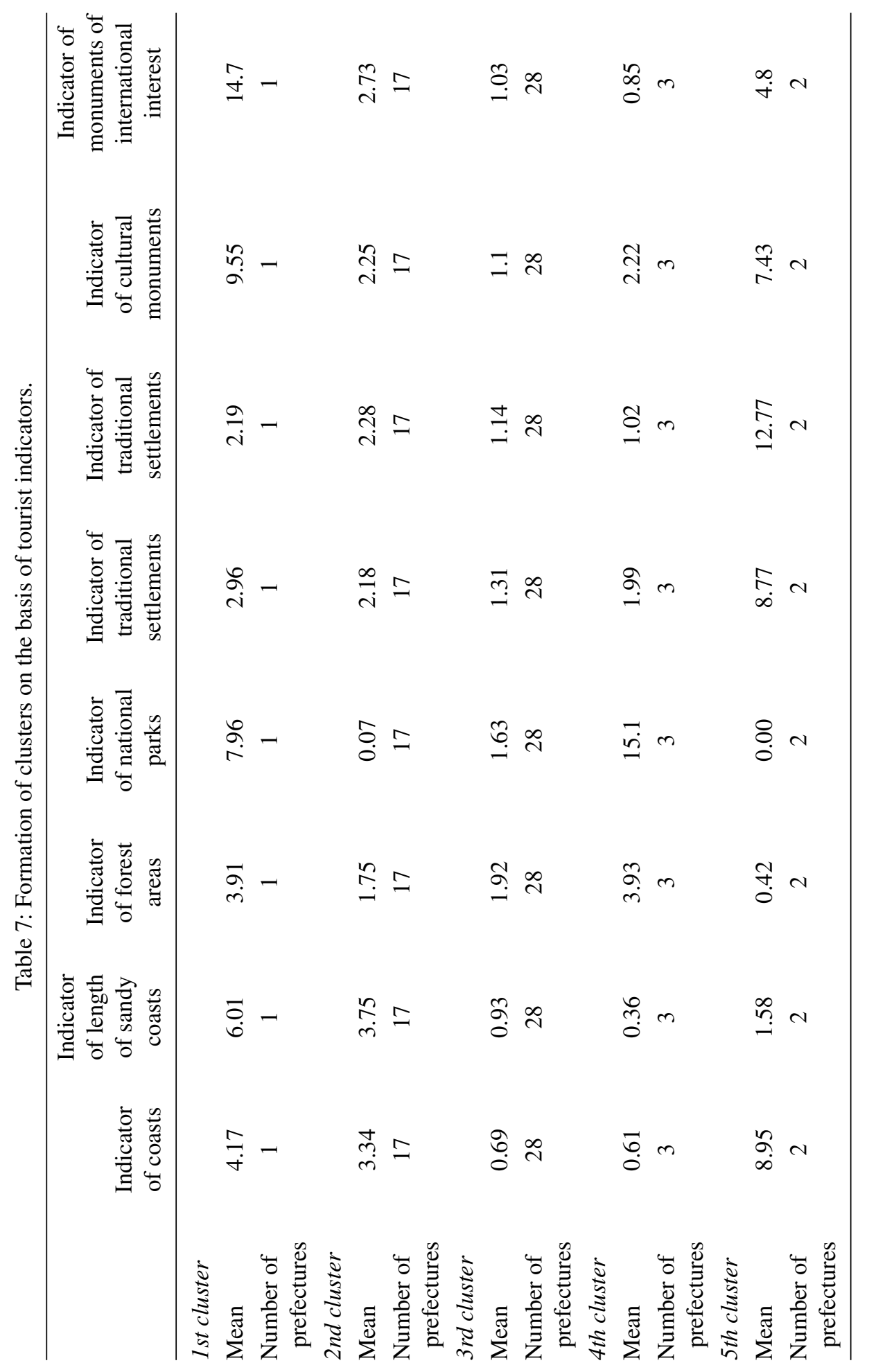


in isolated and rural areas, the creation and increasing demand for certain local agricultural products, the support for the development of local craft-based products, the growth and improvement of local networks and services for transport and communication. In these regions, either small-scale guest houses have been created or traditional houses have been converted in order to offer accommodation to visitors. Furthermore, places have been built where one can have a meal outdoors or enjoy the view, as well as walks, tourist information centers, and local natural history museums.

The fifth territorial unit/cluster, which includes two prefectures (Cyclades, Lakonia) is characterized by the growth of the mass holiday tourism model, and also by cultural tourism. This territorial unit has the highest indicators for beaches, traditional settlements and important traditional settlements. The model of mass tourism has mainly been developed on the Cyclades Islands, and is characterized by the production and provision of a standardized, large-scale tourism product. This product is offered via the tour-operators that cater for its distribution within the market, contributing to a reduction in holiday costs and a spectacular increase in the number of consumer-tourists. Cultural tourism has mainly been developed in Lakonia, which is characterized by a wealth of archaeological and cultural resources (it is home to numerous traditional settlements and monuments of the Byzantine era), as well as beaches.

\section{A FURTHER ANALYSIS}

The above analysis has indicated that, at least for the current linear regression models, several independent variables do not contribute to the prediction of the dependent variable. In addition, the fact that there are several correlated independent variables may contribute to most of the regression coefficients being not statistically significant. Therefore, in order to scrutinize the results we re-estimate the models by using a stepwise variable selection algorithm. In particular, the stepwise variable selection procedure is a model-building method that adopts a forward selection approach except that after a variable is entered, all variables already in the model are examined to determine whether any of them meet the criteria for removal [41]. For the purpose of the present research the variable entry criterion is set to 0.05 whereas the removal criterion is set to 0.10 . However, it should be pointed out that this automated method has been criticized for depending on chance associations amongst variables and that it makes arbitrary choices [41]. The results of the stepwise selection regression analysis are presented in Tables 8 and 9 .

The final model of the dependent variable "nights spent in tourism accommodations" consists of two variables and takes the following form:

Nights spent in tourism accommodations $=5255,518 \mathrm{ARC}+5202 \mathrm{INF}$.

The above model is the outcome of a four-step procedure. At the beginning, the variable that causes the largest change in $R^{2}$ is TRAD and therefore, it first enters the model. In the second step, the regression algorithm selects the variable ARC and re-evaluates the model. In the third step, the entry criteria are met by the variable INF. In the final step, the significance level for the variable TRAD has changed. In particular, the significance level is larger than 0.1 and therefore, the variable is removed from the final model.

The above-mentioned results lead us to the conclusion that the most important independent variables, which influence decisively the "attractiveness" of each prefecture, are "infrastructure" and "archeological sites of international interest." These results do not quite verify our initial expectations because in most cases the construction of tourism-related infrastructure follows tourism demand rather than being a prerequisite.

As regards the final model of the dependent variable "nights spent in hotels", we can see that the regression algorithm has included in the model three independent variables. The final model 
Table 8: Regression coefficients at each step for model (6) with dependent variable "nights spent in tourist accommodations."

\begin{tabular}{|c|c|c|c|c|c|c|c|}
\hline \multirow[b]{2}{*}{ Model } & \multirow[b]{2}{*}{ Variables } & \multicolumn{2}{|c|}{$\begin{array}{l}\text { Unstandardized } \\
\text { coefficients }\end{array}$} & \multirow{2}{*}{$\begin{array}{c}\text { Standardized } \\
\text { coefficients } \\
\text { Beta }\end{array}$} & \multirow{2}{*}{$\begin{array}{c}R^{2} \\
\text { change }\end{array}$} & \multirow[b]{2}{*}{$t$} & \multirow[b]{2}{*}{ Sig. } \\
\hline & & $B$ & SE & & & & \\
\hline \multirow[t]{2}{*}{1} & (Constant) & 8311.359 & 7686.142 & & & 1.081 & 0.285 \\
\hline & TRAD & 5374.316 & 1135.944 & 0.560 & 0.314 & 4.731 & 0.000 \\
\hline \multirow[t]{3}{*}{2} & (Constant) & -3054.154 & 8654.839 & & & -0.353 & 0.726 \\
\hline & TRAD & 4083.107 & 1202.227 & 0.425 & 0.77 & 3.396 & 0.001 \\
\hline & ARC & 4230.414 & 1719.842 & 0.308 & & 2.460 & 0.018 \\
\hline \multirow[t]{4}{*}{3} & (Constant) & -6541.720 & 8388.062 & & & -0.780 & 0.439 \\
\hline & TRAD & 2032.820 & 1433.152 & 0.212 & & 1.418 & 0.163 \\
\hline & ARC & 4386.266 & 1642.657 & 0.319 & 0.66 & 2.670 & 0.010 \\
\hline & INF & 3.836 & 1.607 & 0.331 & & 2.387 & 0.021 \\
\hline \multirow[t]{3}{*}{4} & (Constant) & -5833.139 & 8460.974 & & & -0.689 & 0.494 \\
\hline & $\mathrm{ARC}$ & 5255.581 & 1540.024 & 0.383 & & 3.413 & 0.001 \\
\hline & INF & 5.202 & 1.300 & 0.449 & -0.23 & 4.002 & 0.000 \\
\hline
\end{tabular}

Table 9: Regression coefficients at each step for model (6) with dependent variable "nights spent in hotels."

\begin{tabular}{|c|c|c|c|c|c|c|c|}
\hline \multirow[b]{2}{*}{ Model } & \multirow[b]{2}{*}{ Variables } & \multicolumn{2}{|c|}{$\begin{array}{l}\text { Unstandardized } \\
\text { coefficients }\end{array}$} & \multirow{2}{*}{$\begin{array}{c}\text { Standardized } \\
\text { coefficients } \\
\text { Beta }\end{array}$} & \multirow{2}{*}{$\begin{array}{c}R^{2} \\
\text { change }\end{array}$} & \multirow[b]{2}{*}{$t$} & \multirow[b]{2}{*}{ Sig. } \\
\hline & & $B$ & SE & & & & \\
\hline \multirow[t]{2}{*}{1} & (Constant) & 44347.041 & 15589.081 & & & 2.845 & 0.006 \\
\hline & POP $D=1$ & 1016.282 & 41.637 & 0.961 & 0.924 & 24.408 & 0.000 \\
\hline \multirow[t]{3}{*}{2} & (Constant) & 21307.796 & 12880.476 & & & 1.654 & 0.105 \\
\hline & POP $D=1$ & 894.435 & 39.132 & 0.846 & & 22.857 & 0.000 \\
\hline & INF & 4.820 & 0.855 & 0.209 & 0.030 & 5.639 & 0.000 \\
\hline \multirow[t]{4}{*}{3} & (Constant) & 695.469 & 13163.275 & & & 0.053 & 0.958 \\
\hline & POP $D=1$ & 938.708 & 37.792 & 0.888 & & 24.839 & 0.000 \\
\hline & INF & 3.139 & 0.920 & 0.136 & & 3.413 & 0.001 \\
\hline & TRAD & 7226.298 & 2134.235 & 0.112 & 0.009 & 3.386 & 0.001 \\
\hline
\end{tabular}


has the following form:

$$
\text { Nights spent in hotels }=938,708(\text { POP } D=1)+3139 I N F+7226,298 \text { TRAD. }
$$

In the first step, the variable that causes the largest change in $R^{2}$ is POP with $D=1$ and therefore, it enters the model. The second variable that meets the entry criteria is INF. In the final step, the variable TRAD has a significance level lower than 0.05 and therefore it enters the model.

The results of model (9) are deferent compared with those of model (8). In particular, the most important independent variables in the second model are POP, INF and TRAD. The observed deference between the results of the two models could be due to certain qualitative differences between the two dependent variables. The dependent variable of model (8) depicts the nights spent in tourism accommodations. These are made for exclusively recreational purposes. On the other hand, the dependent variable of model (9) depicts the nights spent in hotels, which possibly includes visits for commercial, recreational, educational or other purposes. In model (9) one of the most important variables is POP. This variable usually influences the visits for other (e.g., educational, commercial) but recreational purposes.

The above results do not quite satisfy our initial expectations as well as the existing theoretical approaches. According to these theoretical schemata, natural resources such as sandy beaches and forest resources should influence significantly tourist attractiveness of each prefecture. The stepwise algorithm for both models has excluded from the final model the variables of "sandy beaches" and "forest resources." Therefore, we conduct a further analysis to thoroughly investigate the relevant relationships. Figure 2A presents the clustered boxplots of the two dependent variables "nights spent in hotels" and "nights spent in tourism accommodation" in relation to the length of sandy beaches. The majority of prefectures with limited stretches of sandy beaches have less overnight stays compared to the prefectures which have medium values in the "sandy beaches" variable. However,
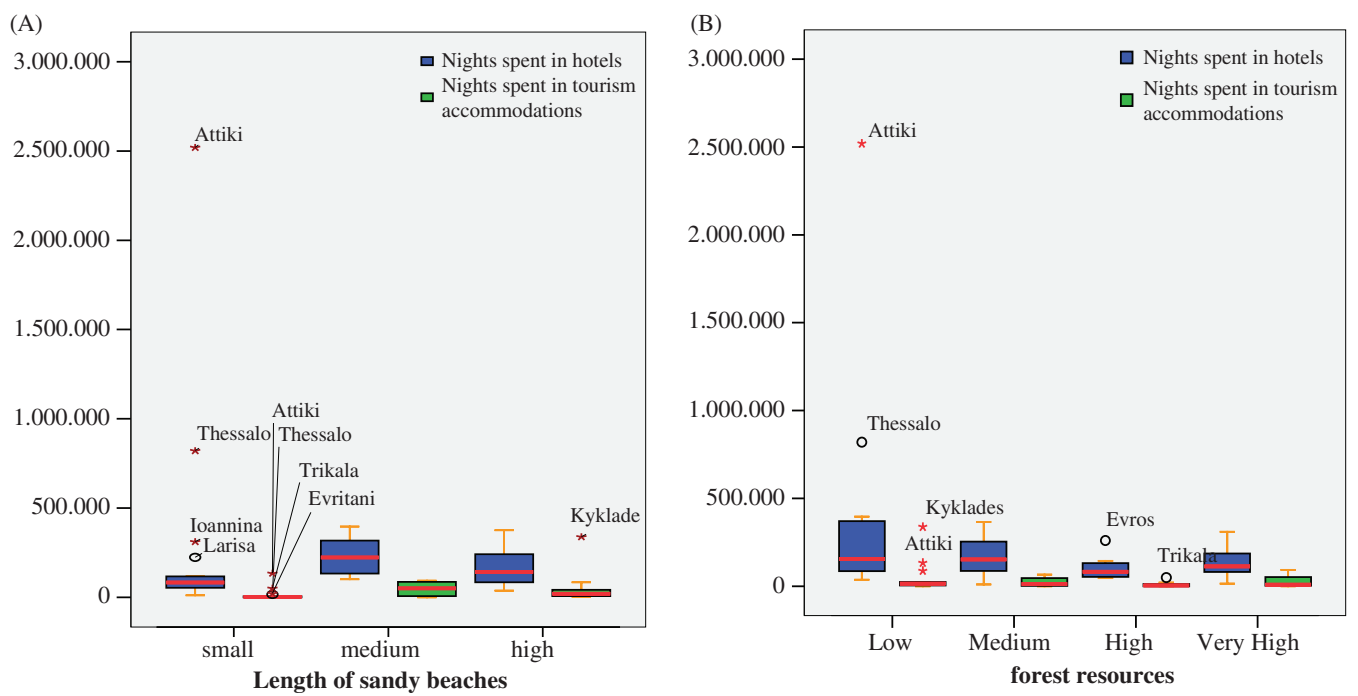

Figure 2: Further investigation of selective relationships. (A) Clustered boxplots of "nights spent in hotels" and "nights spent in tourism accommodation" in relation to the length of sandy beaches. (B) Clustered boxplots of "nights spent in hotels" and "nights spent in tourism accommodation" in relation to the forest resources. 
the existence of extensive sandy beaches does not further improve the total attractiveness of each prefecture. This means that there is a nonlinear relationship between "sandy beaches" and "tourism attractiveness." This is further confirmed by the statistical significance of variable (BEACH) in Table 2 which is 0.1 .

Figure $2 \mathrm{~B}$ presents the relationship between the two dependent variables and the magnitude of forest resources in each prefecture. All four boxplots for the dependent variable "nights spent in hotels" have similar centers. The same applies for the centers of the boxplots that represent the second dependent variable namely "nights spent in tourism accommodations." Therefore, it appears that there is no clear relationship between tourism attractiveness and forest resources at least for the period that has been covered by the present study.

\section{CONCLUSIONS}

The tourism sector plays an essential role in economic and regional development because it could contribute substantially to the next three goals, which each regional policy adopts: (a) economic and social cohesion as tourism provides income in often-remote regions; (b) conservation and management of natural resources and the cultural heritage, which are the main assets in every tourism destination; (c) more balanced competitiveness within the country, as the tourism industry functions very often as a pioneer for the development of other local businesses. Consequently, the tourist sector deserves particular attention and research, specifically in countries such as Greece, a country that is characterized by the intense interregional economic inequalities.

During the post-war period, tourism in Greece and abroad has presented a dynamic course of development, which intensified after 1970. Within this process of tourist growth, much emphasis was laid on the supply side (tourist resources, infrastructure and services) and less on tourism demand, i.e., to the incentives that encourage tourism and travel, and the role of various institutions or professionals in formulating tourist expectations and experiences.

In recent years, an increasing dependency on tour-operators and the intense competition from newly emerging tourist destinations has marked the growth of tourism. This trend has led to changes both in accommodation standards and in general to the "tourist products" on offer, and to tourist activities. It is precisely this wind of change that the promotion of natural, cultural and historical resources and the organization of alternative forms of tourism are attempting to follow.

While the contribution of international tourism has been studied either on a national or regional and local level, we do not yet have any valid and substantial assessment of the structure and contribution of internal tourism to the developmental process.

In the present article, an investigation was made of the main factors that differentiate the structure of internal tourism and their degree of influence on tourist flows in Greece. Furthermore, through the use of relevant statistical data concerning overnight stays, the geographic distribution pattern of tourist activity was examined. It was ascertained that the comparative advantage that is attributed to various regions by the existence of the sea in general or sandy beaches more specifically is the dominant element in formulating overall tourist attractiveness and the subsequent level of tourism in each region. The primary destination points of internal tourism are coastal prefectures. However, the results indicate that the existence of sandy beaches contributes to the growth of tourist attractiveness of a region up to a point. Therefore, the relationship between the two variable is nonlinear. As for the other factors included in the statistical model, we can say that their influence is relatively limited and in several cases statistically insignificant. In summary, we can deduce, as observed by others [2], that internal tourism demand is characterized as a dimorphic concentration with regard to its spatial structure and the time period during which it is present. 
The estimated model could also be used as a prediction model, but based on the reservations that were stated in relation to the possibility of reliably forecasting the tourism development activity. These reservations refer to the basic weakness of the prediction methods to include the "heterogeneity of the future," that is the difference between the future and the present or past [2].

In the typological analysis, two uniform territorial units of tourist attractiveness are determined by using the tourist resource indicators. The first territorial unit concerns the coastal prefectures, and is mainly characterized by the growth of the mass holiday tourism model and secondly by the model of cultural tourism. The second territorial unit, which comprises the mainland prefectures, is dominated by the model of countryside tourism and particularly the model of special and alternative forms of tourism that can progressively contribute to an integrated development of the countryside.

Both due to the restrictions and the methodological context, within which the present research was performed, the conclusions, which arise from the preceding analysis, can constitute the basis for a scientific debate on the subject. The contribution of scientific approaches from other sectors related to tourism (economy, sociology, geography) through the use of various methodological tools (analysis of motives or characteristics of tourist travels, calculation of expense, assessment of demand in tourist regions, etc.) is conducive to a multifaceted analysis of the subject at hand. Nevertheless, we believe that the main conclusions reached do identify the basic effect of each individual factor on internal tourism. Moreover, based on the indicators, which essentially shape tourist attractiveness, the typology of the mainland prefectures is proposed. Finally, we would like to point out that the sole subject of our research was tourist travel and not a broader exploitation of regions for tourism. This constitutes a separate subject and is related moreover to the regions' general residential development, and the construction of second or summerhouses in these areas, which is a matter that merits a different form of consideration and study.

\section{REFERENCES}

[1] Coccosis, H. \& Tsartas, P., Sustainable Tourism Development and Environment, Editions Kritiki: Athens, 2001.

[2] Varvaresos, S., Tourism Economic Approaches, Editions Propobos: Athens, 2000 (in Greek).

[3] NSSG, Tourist Statistics, NSSG: Athens, 2005 (in Greek).

[4] Polyzos, S. \& Arabatzis, G., A multicriteria approach for the evaluation of tourist resources of Greek prefectures. Tourism Today, 6, pp. 96-111, 2006.

[5] Polyzos, S., Arabatzis, G. \& Tsiantikoudis, S., The attractiveness of archaeological sites in Greece: a spatial analysis. International Journal of Tourism Policy, 1(3), pp. 246-266, 2007.

[6] Polyzos, S. \& Sdrolias, L., Strategic method of confrontation of tourist competition: the case of Greece. Journal of Travel and Tourism Research 6(1), pp. 12-28, 2006.

[7] Buhalis, D., Tourism in Greece: strategic analysis and challenges. Current Issues in Tourism, 4(5), pp. 440-480, 2001.

[8] Tsartas, P., Tourists, Travels, Locations: Sociological Approaches in Tourism, Editions Enantas: Athens, 1996 (in Greek).

[9] NSSG, Tourist Statistics - Years 1991-1993, Athens, 1995, (in Greek).

[10] NSSG, Tourist Statistics - Years 1995-1996 Unpublished data, Athens, 1998 (in Greek).

[11] NSSG, Tourist Statistics - Years 1996-1998, Unpublished data, Athens, 2000 (in Greek).

[12] Monk, J. \& Alexander, C.S., Free port fallout: gender, employment and migration on Margarita island. Annals of Tourism Research, 13(3), pp. 393-414, 1986.

[13] Komilis, P., Tourism and sustainable regional development. Tourism: The State of the Art, eds G. Seaton et al., Wiley and Sons: Chichester, pp. 65-73, 1995. 
[14] Polyzos, S., Analysis of factors that influence the internal tourist flows in Greece. Topos, 18-19, pp. 87-108, 2002 (in Greek).

[15] Sindiga, L., Domestic tourism in Kenya. Annals of Tourism Research, 23(1), pp. 19-31, 1996.

[16] Knight, J., Hospitalities in Japanese rural tourism. Annals of Tourism Research, 13(3), pp. 367-393, 1996.

[17] Marcouiller, D., Kim, K.-K. \& Deller, S., Natural amenities, tourism and income distribution. Annals of Tourism Research, 31(4), pp. 1031-1050, 2004.

[18] Komilis, P., Spatial Analysis of Tourism, KEPE: Athens, 1986 (in Greek).

[19] Christopoulou, O. \& Papadopoulos, I., Winter tourism, development of mountainous areas and visitors' attitudes towards landscape protection. Anatolia, 12(2), pp. 153-164, 2001.

[20] Tsartas, P., Manologlou, H. \& Markou, A., Qualitative Aspects and Demand Trends of Domestic Tourism. NCSR: Athens, 2001 (in Greek).

[21] Konsolas, N., Contemporary Regional Economic Policy. Editions Papazisi: Athens, 1997 (in Greek).

[22] Richardson, H., Regional Economics, Editions Papazisi: Athens, 1972.

[23] Walker, D. \& Chapman, K., Location of Industry, Editions Papazisi: Athens, 1992.

[24] Labrianidis, L., Elements of Economic Geography, Editions Pattakis: Athens, 2002 (in Greek).

[25] Christaller, W., Some considerations of tourism location in Europe: the peripheral regions underdeveloped countries - recreation areas. Papers of Regional Science Association, XII, pp. 95-105, 1963.

[26] Von Boventer, E., Land values and spatial structure. Papers of Regional Science, 18, pp. 231-242, 1966.

[27] Pearce, D., Tourism Today: A Geographical Analysis, Longman: London, 1991.

[28] Long, W.L., The economics of travel gravity models. Journal of Regional Science, 10(3), pp. 353-363, 1970.

[29] Gordon, I.R. \& Edwards, S.L., Holiday trip generation. Journal of Transportation Economics and Policy, 7(2), pp. 153-168, 1973.

[30] Lagos, D., Tourism and regional development. Topos, 14, pp. 47-65, 1998 (in Greek).

[31] Clark, C., Wilson, F. \& Bradley, J., Industrial location and economic potential in Western Europe. Regional Studies, 3, pp. 197-212, 1969.

[32] Keeble, D., Owens, P.C. \& Tompson, C., Regional accessibility and economic potential in the European Community. Regional Studies, 16, pp. 419-432, 1982.

[33] Ministry of Finance, Strategic Plan for the Development of Railway Infrastructure - Greece 2010, Dromos A.E.M., 2, 1993 (in Greek).

[34] Martin, C. \& Witt, S., Accuracy of econometric forecasts of tourism. Annals of Tourism Research, 16, pp. 407-428, 1989.

[35] Kavvadias, P., Indicators of Regional Development in Greece, KEPE: Athens, 1982 (in Greek).

[36] Everrit, B., Cluster Analysis, 3rd edition, Arnold: London, 1993.

[37] Hair, J., Andersan, R., Tatham, R. \& Black, W., Multivariate Data Analysis with Readings, 5th edition, Prentice Hall, International, Inc.: NJ, USA, 1998.

[38] Laws, E., Conceptualizing visitor satisfaction management in heritage settings: an exploratory blueprinting analysis of Leeds Castle, Kent. Tourism Management, 19(6), pp. 545-554, 1998.

[39] Soutsas, K., Tsantopoulos, G., Arabatzis, G. \& Christopoulou, O., Characteristics of tourism development in mountainous regions using the categorical regression: the case of Metsovo (Greece). International Journal of Sustainable Development and Planning, 1, pp. 32-45, 2006. 
[40] Papageorgiou, A. \& Arabatzis, G., Protected natural areas and biodiversity in Greece: social, political and developmental dimensions. Scientific Annals of the Department of Forestry and Natural Environment (Dedicated to Dr. L. Arvanitis, Emeritus Professor), A.U.Th. Vol. MA/1998, pp. 713-733, 1998.

[41] Norusis, M., SPSS 14.0: Statistical Procedures Companion, Prentice Hall: NJ, 2005. 